\begin{tabular}{|l|l|}
\hline $\begin{array}{l}\text { Postprint } \\
\text { Version }\end{array}$ & 1.0 \\
\hline Journal website & $\frac{\text { http://pediatrics.aappublications.org/content/early/2014/07/09/peds.2013- }}{\underline{3225 . a b s t r a c t}}$ \\
\hline Pubmed link & $\underline{\text { http://www.ncbi.nlm.nih.gov/pubmed/25022739 }}$ \\
\hline DOI & $10.1542 /$ peds.2013-3225 \\
\hline
\end{tabular}

This is a NIVEL certified Post Print, more info at http://www.nivel.eu

\title{
Pediatric Drug Formulations: A Review of Challenges and Progress
}

\author{
Verica IVANovska, PharmD, MPH ${ }^{\mathrm{A}, \mathrm{B}}$, CARIN M.A. Rademaker, PharmD, PhD ${ }^{\mathrm{C}}$, Liset \\ VAN DIJK, PHD ${ }^{\mathrm{D}}$, AND AUKJE K. MANTEL-TEEUWISSE, PHARMD, PHD ${ }^{\mathrm{A}}$ \\ ${ }^{a}$ Utrecht Institute for Pharmaceutical Sciences, Utrecht University, Utrecht, Netherlands; \\ ${ }^{\mathrm{b}}$ Faculty of Medical Sciences, University Goce Delcev, Republic of Macedonia; \\ ${ }^{\mathrm{c}}$ Department of Clinical Pharmacy, University Medical Center Utrecht, Utrecht, Netherlands; \\ and \\ ${ }^{d}$ NIVEL, Netherlands Institute for Health Services Research, Utrecht, Netherlands
}

\begin{abstract}
Children differ from adults in many aspects of pharmacotherapy, including capabilities for drug administration, medicine-related toxicity, and taste preferences. It is essential that pediatric medicines are formulated to best suit a child's age, size, physiologic condition, and treatment requirements. To ensure adequate treatment of all children, different routes of administration, dosage forms, and strengths may be required. Many existing formulations are not suitable for children, which often leads to off-label and unlicensed use of adult medicines. New regulations, additional funding opportunities, and innovative collaborative research initiatives have resulted in some recent progress in the development of pediatric formulations. These advances include a paradigm shift toward oral solid formulations and a focus on novel preparations, including flexible, dispersible, and multiparticulate oral solid dosage forms. Such developments have enabled greater dose flexibility, easier administration, and better acceptance of drug formulations in children. However, new pediatric formulations address only a small part of all therapeutic needs in children; moreover, they are not always available. Five key issues need to be addressed to stimulate the further development of better medicines for children: (1) the continued prioritization of unmet formulation needs, particularly drug delivery in neonates and treatment gaps in pediatric cancers and childhood diseases in developing countries; (2) a better use of existing data to facilitate pediatric formulation development; (3) innovative technologies in adults that can be used to develop new pediatric formulations; (4) clinical feedback and practice-based evidence on the impact of novel formulations; and (5) improved access to new pediatric formulations.
\end{abstract}




\section{Abbreviation:}

WHO — World Health Organization

Drug formulations used in pediatric pharmacotherapy should be adapted to children's needs to suit their age, size, physiologic condition, and treatment requirements. ${ }^{1,2}$ Such pediatric medicines are key to achieving safe and accurate dose administration, reducing the risk of medication errors, enhancing medication adherence, and improving therapeutic outcomes in children.,

The use of inadequate drug formulations in children may pose problems not seen in adults, such as difficulty in swallowing conventionally sized tablets, safety issues with certain excipients that are acceptable in adult formulations, and adherence problems with unpalatable medicines. ${ }^{1,5}$ These issues have led to tragedies in the past, and they exist partly because only a small fraction of all marketed drugs are available in formulations that are age appropriate. ${ }^{6-12}$ As a result, many adult medicines are used off-label in children, a practice that carries additional health and environmental risks. ${ }^{13-15}$

To strengthen the development of pediatric drug formulations, new legislation was introduced in the United States and Europe, and efforts for global collaboration were made by the World Health Organization (WHO). ${ }^{16-20}$ A number of innovative pediatric formulations have followed, but their actual effect on pediatric drug approvals remains to be seen, as clinical trials and marketing authorization take a substantial amount of time. ${ }^{21-24}$

To optimize pharmacotherapy in children, it is important for clinicians to understand the background of the aforementioned problems as well as to gain insight into the challenges, developments, and potential solutions. The aim of the present review was to describe why there is a specific need for pediatric drug formulations and to illustrate the clinical consequences of the absence of suitable medicines for children. We will discuss the progress achieved so far and determine additional steps required to improve the development and availability of pediatric drug formulations.

\section{The Necessity of Pediatric Drug Formulations}

\section{Diversity in Children}

It has been well established that children are not small adults but rather a distinct and heterogeneous patient group with regard to pharmacotherapy. ${ }^{25}$ They often exhibit a different response to both active substance and excipients. ${ }^{26}$ Children present a continuum of growth and developmental phases as a result of their rapid growth, maturation of the body composition, and physiologic and cognitive changes during childhood.

Children differ from adults in many aspects of pharmacokinetics and pharmacodynamics, potential routes of administration, medicine-related toxicity, and taste preferences. ${ }^{3,25}$ Important pharmacokinetic differences between children and adults include the rate of gastric emptying and $\mathrm{pH}$, gastrointestinal permeability, and the surface area available for drug absorption. Dissimilarities have also been reported in drug metabolism, transporter expression, biliary function, and renal clearance, resulting in differences in drug disposition and elimination. ${ }^{27,28}$ The largest deviation from adult pharmacokinetics is observed in the first 12 to 18 months, when organ functions are developing. ${ }^{29,30}$ In older children and adolescents, the pharmacokinetic parameters approach adult values and are thus easier to predict. ${ }^{26,31-33}$ The effect of age on pharmacokinetics leads to different dosing requirements for different age 
groups. From birth to adulthood, the body size and weight of an average child increases up to 20-fold, and the magnitude of dose variation administered throughout childhood may be 100 -fold. ${ }^{5}$ More dramatically, premature neonates admitted to the hospital can weigh as little as $500 \mathrm{~g}$, further highlighting the need for dose variability. ${ }^{29,30}$ Maturation processes in children are not linear, and therefore doses in certain age subsets may be lower, identical to, or higher than in adults, depending on a drug's metabolic pathway. ${ }^{32,34,35}$

Due to this extensive variability in children, there is an obvious need for drug formulations tailored to children in all the target age groups. The International Conference of Harmonisation divides childhood into 5 age groups related to the developmental stages, derived from the physiologic and pharmacokinetic differences mentioned earlier. ${ }^{28}$ These groups (with age ranges) are: preterm newborn infants; term newborn infants (0-27 days); infants and toddlers (1-23 months); children (211 years); and adolescents (12-16 years in the United States or 12-18 years in the European Union). ${ }^{5,36}$

The European Committee for Medicinal Products for Human Use further subdivides the age group “children” (2-11 years) into "preschool children” (2-5 years), and "school children" (6-11 years) to more precisely reflect the children's ability to accept and use different dosage forms. ${ }^{5}$ However, the classification of the pediatric population into age categories is to some extent arbitrary because children of the same chronologic age may still develop at different rates. ${ }^{28}$

\section{Age-Related Adherence to Pediatric Drug Formulations}

Formulation acceptability and preferences facilitate medication adherence in children, and they are important factors in achieving the intended treatment outcomes. Formulation acceptability differs across age groups as children gradually develop their cognitive and motor skills, and improve their ability to swallow medications. At certain ages, the dependence on caregivers also plays a role in the administration of pediatric dosage forms. ${ }^{1}$ Pain, discomfort, and an unnecessary burden on children and/or caregivers during drug administration should be minimized to assure adequate medication adherence. In older children and adolescents, lifestyle and peer pressure may also influence medication adherence and possible preferences for particular formulations.

Taste attributes may be critical to ensure acceptable adherence to pediatric oral formulations. Because children have a low tolerance for disagreeable taste, the use of tasteless or palatable medicines can minimize the loss of medication from spillage and/or spitting. ${ }^{14,37,38}$ Taste preferences may differ between children and adults, as children prefer sweet and salty flavors, and dislike bitter and peppermint taste. These findings suggest that taste assessment should involve children early in the drug formulation development. ${ }^{35,38,39}$ Children's communication about taste perceptions can be facilitated by using age-appropriate methods, scales, and measures. ${ }^{40}$ Alternative taste-screening methods may include adult taste panels with validated design for data transferability or predictive electrochemical sensor systems (so called "electronic tongues"). ${ }^{41,42}$ 


\section{Clinical Consequences of the AbSence of Suitable Pediatric Drug FORMULATIONS}

\section{Potential Limitations of Pediatric Drug Formulations}

Historically, the failure to appreciate the developmental changes in children has led to many adverse outcomes in clinical practice. Examples include infant deaths from choking on albendazole tablets, the lethal use of benzyl alcohol or diethylene glycol in sulfanilamide elixirs, and electrolyte imbalances caused by high contents of sodium or potassium in parenteral formulations. ${ }^{6-9}$

To prevent such tragedies and ensure adequate treatment of children of all ages, different routes of administration, dosage forms, and strengths are often needed for the same active substance. ${ }^{1}$ Table 1 illustrates the specific purposes, potential strengths, and weaknesses of various routes of administration and dosage forms for pediatric use. ${ }^{1,2,5,43-47}$ As in adults, the oral route is the predominant route of administration in children. ${ }^{1,2,43}$ Alternative nonoral routes of administration include rectal, dermal, nasal, pulmonary, and ocular routes. ${ }^{1,2}$

\section{[TABLE 1]}

Potential Clinical Advantages and Disadvantages of Different Formulations and Routes of Administration in Children ${ }^{1,2,5,43-47}$

The selection for clinical use is influenced by the limitations of each dosage form. Oral solids are associated with the risk of choking or chewing and with limited dose flexibility, whereas palatability and dose uniformity may be challenging for liquid preparations. ${ }^{1,2,43,44}$ In addition, liquid forms raise issues regarding stability (chemical, physical, or microbiological) and the requirement for clean water; moreover, they can be bulky, impractical, and expensive to ship and store, particularly in lower income countries with hot and humid climates. ${ }^{48,49}$ The use of nonoral routes of drug administration may be hampered by difficult application, local irritation, fluid overload, electrolyte imbalance, or poor drug acceptability (Table 1). ${ }^{1,2,5,43-47}$ In neonates, intravenous administration may lead to volume overload. Moreover, measuring small dose volumes may cause large dosage variations and errors. ${ }^{47}$ Similarly, age-appropriate dosing volumes are important to ensure full dose ingestion for oral liquids. ${ }^{5}$

Another important concern in pediatric drug formulations are the excipients, frequently used as preservatives, sweeteners, fillers, solvents, and coating and coloring agents. Their selection for pediatric medicines is challenging because neither the inactive ingredients guide list of the US Food and Drug Administration nor the "generally regarded as safe" status has been validated for pediatric use. ${ }^{3,29,30,50}$ Little is known about the safety of excipients in children, and accepted daily and cumulative intakes of excipients have not been established. Anecdotal evidence suggests an association between some excipients commonly used in adult medicines and elevated toxicity and safety issues in children, especially neonates (Table 2). ${ }^{3,6-9,26,50-60}$ A recent example is the administration of lopinavir/ritonavir (Kaletra [Abbott Laboratories, Abbott Park, IL]) oral solution in premature newborns who were exposed to the risk of ethanol and/or propylene glycol toxicity. This situation resulted in a Food and Drug Administration drug safety communication and a change in the drug label in $2011 .{ }^{61}$ A number of recent studies in NICUs revealed systemic concentrations of excipients that were intolerable even in older age groups. ${ }^{54,62,63}$ 


\section{[TABLE 2]}

Examples of Excipients With Elevated Toxicity and Safety Risks for (Preterm and Term) Newborns and Infants $<6$ Months of Age , $^{7,8,53-60}$

The urgent need to understand these safety concerns has led to a collaborative effort by the United States and the European Union to create a STEP (Safety and Toxicity of Excipients for Pediatrics) database. Its aim is to improve systematic data collection on excipient toxicity and tolerance in children. ${ }^{64-66}$ A similar initiative, ESNEE (European Study of Neonatal Exposure to Excipients), has developed a platform for the systematic assessment of excipients in neonates. ${ }^{67}$

\section{Concerns Over Off-label and Unlicensed Use of Medicines in Children}

Pediatric drug development is associated with numerous challenges, including methodologic and ethical requirements for pediatric trials, high developmental costs, and a small and fragmented market. ${ }^{3,4,50,68-71}$ As a result of these challenges, there have only been limited research efforts to adapt medicines according to pediatric needs. Thus, only one-third of all medicines approved by the European Medicines Agency over the period of 1995 to 2005 were licensed for use in children. ${ }^{11,23,72}$ Higher but still unsatisfactory rates were reported in New Zealand (35\%), Australia (38\%), and the United States (54\%). ${ }^{23,73,74}$ The pediatric market has focused mostly on only a limited number of therapeutic areas, such as antiinfectives, hormones, and medicines for the respiratory and central nervous system. ${ }^{75}$ Meanwhile, there are hardly any dermal preparations and medicines specifically aimed at younger age groups for the cardiovascular system, sensory organs, and cancers. ${ }^{23}$ Moreover, especially in younger children and neonates, even authorized pediatric medicines may not always be age appropriate with respect to dosing, suitability of dosage forms, and excipients.

This lack of pediatric formulations often leaves health care professionals no alternative but to use adult medicines in an off-label or unlicensed manner. The trend is widespread: in the European Union, $45 \%$ to $60 \%$ of all medicines are given to children off-label. This trend is also true for $90 \%$ of medicines administered to neonates and infants, particularly in PICUs. ${ }^{76}$ Not surprisingly, off-label use is common for antiarrhythmics, antihypertensives, proton pump inhibitors, $\mathrm{H}_{2}$-receptor antagonists, antiasthmatic agents, and some antidepressants. ${ }^{76}$ In the United States, two-thirds of medicines used in pediatrics are off-label; worldwide, this proportion is up to three-quarters. ${ }^{77}$

\section{Risk Management of Compounding and Manipulation of Medicines for Children}

Alternative treatment options are often used to make unavailable drugs accessible for children and/or to adjust drug doses according to individual patient needs. These options include the modification of administration routes (eg, oral use of parenteral formulations); manipulation of adult dosage forms (eg, diluting liquid formulations); segmenting tablets and suppositories, cutting patches, and dispersing open capsules or crushed tablets in water, liquid, or food; or extemporaneous dispensing (ie, compounding medicines from ingredients within pharmacies). ${ }^{5,78}$

Administering medicines in this way is difficult and unsafe because limited data are available to validate stability, bioavailability, pharmacokinetics, pharmacodynamics, dosing accuracy, tolerability, and reproducibility. ${ }^{79-84}$ A documented example is the crushing of Kaletra tablets for pediatric administration, which resulted in reduced 
bioavailability and drug exposure in children. ${ }^{85}$ All these manipulations may compromise drug efficacy and/or safety, as well as create risks for the environment and individuals handling the dosage forms, particularly in the case of mutagen and cytotoxic compounds. ${ }^{79-84}$

Producing a medicine by extemporaneous dispensing may be the only option for some children to receive a certain medicine in a suitable dosage form. In such situations, the risks can be reduced by applying sound quality assurance systems. Pharmacists should ensure that good manufacturing principles are implemented, adequate raw materials and formulae are used, and stability studies are validated and conducted by certified laboratories. Moreover, because practices and guidelines for extemporaneous formulations differ greatly among practitioners, there is an urgent need for a standardization of commonly applied compounding practices. ${ }^{78,86}$ Existing networks, resources, and guidelines should be stimulated to provide appropriate information on the standards of practice for extemporaneous formulations. ${ }^{78,84}$ However, the available information may not always be easily transferable to a local situation or may not be exclusively focused on children. ${ }^{87}$

\section{Progress in Developing Pediatric Drug Formulations}

\section{New Frameworks for the Development of Pediatric Drug Formulations}

To overcome the aforementioned challenges, a new pediatric regulatory environment has been created to stimulate the development and availability of age-appropriate medicines for children. ${ }^{16-19}$ The intended long-term aim is to integrate pediatric needs into overall drug development, so that each new component is systematically evaluated for its potential use in children. Initial progress has been made by combining legal requirements with incentives for companies to test, authorize, and formulate medicines for use in children. Over the past decade, the Best Pharmaceuticals for Children Act and the Pediatric Research Equity Act in the United States, and the Pediatric Regulation in the European Union, have fueled an increasing number of pediatric clinical trials and innovations in pediatric drug formulations. $^{22,24}$

Nonetheless, therapeutic areas addressed by the industry seem to be more aligned with adult drug development than with unmet public health needs in children.22,68,88,89 To guide the efforts toward significant therapeutic benefits for children, the US and European Union government agencies have produced priority medicines lists, highlighting areas with substantial off-label use in children and gaps in pediatric data. $^{90,91}$

Simultaneously, a WHO initiative ("Make Medicines Child Size”) has drawn attention to the fact that the lack of medicines most acutely affects children living in developing countries. ${ }^{20,92}$ A focus on the development of suitable dosage forms to treat diseases of high burden in childhood in low-resource settings could greatly reduce childhood morbidity and mortality. ${ }^{92}$ There have been comprehensive WHO activities to improve access to and use of safe and appropriate pediatric medicines. These activities include establishing a model list of essential medicines for children and a list of priority life-saving medicines for women and children, developing model formularies for children, updating childhood treatment recommendations, and including pediatric medicines in the prequalification process. ${ }^{93-97}$

Furthermore, the present reward system has not proved to be an adequate incentive for investment in off-patent drug research. ${ }^{69,89}$ This tendency may be linked to 
prescription reimbursement rules that attach little value to old medicines, even if they include new child-friendly formulations. ${ }^{69}$ To generate more interest in off-patent medicines, new public funding opportunities in academia and small- and mediumsized enterprises have been provided by both the US Eunice Kennedy Shriver National Institute of Child Health and Human Development Pediatrics Formulation Initiative and the EU's Seventh Framework Program for Research. ${ }^{98-100}$ However, new technologies developed from these initiatives must be adopted by the industry and marketed so they can realize their full potential.

There is also increased recognition that the selection of appropriate pediatric formulations requires a risk/benefit analysis on a case-by-case basis. ${ }^{1,2}$ Taking into consideration the heterogeneity of children and specific characteristics of each dosage form (Table 1), the industry has recently proposed a composite assessment tool to guide optimal formulation choices for individual patients. ${ }^{44}$ This structured framework is based on 3 predetermined criteria for each drug formulation: product efficacy and ease of use (eg, dose flexibility, drug acceptability, convenient handling, correct use), patient safety (eg, bioavailability of active substances, safety of excipients, medication stability, risk of medication errors) and patient access (eg, product manufacturability, affordability, development, production speed). ${ }^{41}$ The choice between alternatives is based on a quantitative scoring system for each pharmaceutical formulation option. ${ }^{44}$ This individualized approach to optimal formulations can also be replicated in clinical settings if the selection criteria include relevant aspects of patient care.

\section{Novel Oral Pediatric Formulations}

Recent progress in pediatric drug development mostly concerns oral formulations. ${ }^{22,101}$ Until recently, liquid formulations were preferred for younger children because of their easy and simple dosing across age subgroups. ${ }^{5,10,102}$ In 2008, a WHO expert forum proposed a paradigm shift toward pediatric oral solids in view of stability problems and the high transportation and storage costs involved in liquid formulations. ${ }^{92}$ From then on, flexible oral solid dosage forms, such as orodispersible tablets and/or tablets used to prepare oral liquid preparations suitable for younger children, have become the recommended pediatric dosage forms worldwide. In 2009, Coartem Dispersible (Novartis International AG, Basel, Switzerland, and Medicines for Malaria) was launched to offer flexible artemisininbased combination therapy for children (5-35 kg) with a cure rate comparable to that of the Coartem tablet. ${ }^{103,104}$

For oral medicines requiring precise dose measurement, a new flexible platform technology was proposed to produce solid multiparticulate dosage forms (eg, minitablets, pellets) and dosage forms dispersible in liquids or sprinkled on food. ${ }^{92}$ This platform technology has the potential flexibility to construct fixed-dose combination products, especially for chronic diseases such as HIV or tuberculosis. ${ }^{105-107}$ Table 3 illustrates some of the quality-certified, innovative oral pediatric dosage forms brought to market, including much needed heat-stable formulations and fixed-dose combination products for low-resource settings. ${ }^{97,104,108-116}$

\section{[TABLE 3]}

Examples of Recently Marketed/Prequalified Novel Oral Drug Formulations for Children ${ }^{97,104,108-116}$ 
Current surveys reveal that novel oral solids may be used in children at an earlier age than previously anticipated. ${ }^{5,117,118}$ Initially, in 2009, Thomson et al $^{119}$ demonstrated that $46 \%$ of 2 -year-old children and $86 \%$ of 5 -year-old children could swallow innovative 3-mm mini-tablets without choking or aspiration. The age limit was further decreased in an exploratory study which demonstrated that children aged 6 to 12 months were capable of swallowing uncoated, drug-free, 2-mm mini-tablets and accepted them better than sweet liquid formulations. ${ }^{120,121}$ For infants aged $<2$ years, a new promising development is the orally disintegrating mini-tablet, which combines mini-tablets and fast-dissolving dosage forms. ${ }^{111}$

A complementary research area is the development of pediatric dosing devices, which facilitate the accurate and consistent administration of oral pediatric formulations. ${ }^{1,122}$ New devices generally assist the oral delivery of liquids to small children by using modified feeding bottles and pacifiers with medicines placed in a reservoir, help improve the palatability of oral solutions by using a dose-sipping technology, or help increase product stability by using a pulp-spoon with a single dry dose of medicine (see Table 4 for more detailed examples). ${ }^{3,116,122}$

\section{[TABLE 4]}

\section{FUTURE STEPS}

The ideal pediatric formulation should have flexible dosage increments and minimal excipients, be palatable, safe and easy to administer, and be stable with regard to light, humidity, and heat. Nevertheless, a significant number of drug formulations are unsuitable for children, which leads to unsafe off-label and unlicensed use of adult medicines. Recent initiatives promoting pediatric drug development have made some initial progress in the neglected area of pediatric formulations. Most efforts have focused on age-appropriate oral solid preparations, which enable dose flexibility, easier administration, and better acceptance in children. Despite these advances, the new pediatric formulations are still only a small part of the full therapeutic arsenal needed to serve all pediatric patients.

The following 5 priorities have been identified as critical for the further development of appropriate pediatric formulations. The first key issue is the continuous prioritization process that focuses on unmet public health issues and ensures that drug development aligns with the true clinical needs in children. Special attention should be paid to innovations that improve drug delivery in neonates, fill treatment gaps in pediatric cancers, and treat diseases of high burden in developing countries. $^{49,90,91,94,123}$

Second, better use of existing data are required to facilitate pediatric drug development. Some innovative scenarios under investigation include preliminary "enabling” formulations that bridge existing adult formulations and potential pediatric market formulations, adjustments of adult in vitro gastrointestinal models to study drug bioavailability in children, and refined criteria for the extrapolation of adult efficacy data to the pediatric population. ${ }^{124-126}$

Third, future research on pediatric formulations could potentially benefit from existing or innovative technologies under development in adults. ${ }^{127}$ Novel experimental treatments of adult cancers, infections, and asthma have used nanoparticle-targeted therapy, novel smart polymer-based drug delivery systems, new chemical entities (eg, dendrimers), and remote triggering devices. These 
treatments may have significant applications in children, and the identification of appropriate animal models for pediatric preclinical studies should be a research priority. ${ }^{128-130}$

Fourth, ongoing technologic advances need to be accompanied by relevant patient outcome studies and clinical feedback on efficacy, safety, patient acceptability, preferences, and adherence regarding new formulations; currently, such studies and feedback are lacking. ${ }^{131}$ Practice-based evidence on the impact of novel formulations, generated by health care professionals and caregivers, could provide further support for the development of pediatric medicines with clear clinical advantages.

The fifth priority concerns finance. Because innovative technologies are costly, the ultimate challenge is to make these new pediatric formulations available on the market and in daily practice. ${ }^{22,89,132}$ Their commercial viability might be improved by an increased market size (eg, global scale, inclusion of geriatric patients and adults with swallowing difficulties); new incentive schemes (particularly for off-patent drugs), such as limited exclusivity and premiums, funding, and tax breaks; and public-private partnerships that support the development of orphan drugs and other less profitable niches. ${ }^{69,98-100}$

In sum, to reach these goals, it is essential that there is a committed collaboration between stakeholders that extends across disciplines and geographic regions.

Moreover, this collaboration should have the innovative potential to further shape the pediatric drug development agenda and thus to close the adult-child medicine gap.

\section{ACKNOWLEDGMENT}

We acknowledge Dr Richard Laing (WHO) for his advice on the progress analysis and recommendations for improving pediatric drug formulations.

\section{FOOTNOTES}

Address correspondence to Verica Ivanovska, PharmD, MPH, Utrecht Institute for Pharmaceutical Sciences, Utrecht University, PO Box 80082, 3508 TB, Utrecht, Netherlands. E-mail: vericaivanovska@hotmail.com

Dr Ivanovska conceptualized and designed the study, and drafted the initial manuscript; Drs Rademaker, van Dijk, and Mantel-Teeuwisse contributed to the study concept and outline, and reviewed and revised the manuscript; and all authors approved the final manuscript as submitted.

FINANCIAL DISCLOSURE: The authors have indicated they have no financial relationships relevant to this article to disclose.

FUNDING: No external funding. POTENTIAL CONFLICT OF INTEREST: Dr van Dijk's institute (NIVEL) has received research funds from Astra Zeneca, Bristol-Myers Squibb, and Pfizer for studies not related to the present study. Dr Mantel-Teeuwisse receives no direct funding or donations from private parties, including the pharmaceutical industry. Research funding from public/private partnerships (ie, TI Pharma [www.tipharma.nl]) has been accepted under the conditions that no company-specific product or company-related study is conducted. She has received unrestricted research funding from public sources (ie, the Netherlands Organisation for Health Research and Development [ZonMW], the EU 7th Framework Program [FP7], the Dutch Medicines Evaluation Board [MEB], and the Dutch Ministry of Health). Dr 
Ivanovska, V., Rademaker, C.M.A., Dijk, L. van, Mantel-Teeuwisse, A.K. Pediatric drug formulations: a review of challenges and progress. Pediatrics: 2014, 134(2), 361-372

Ivanovska and Dr Rademaker have indicated they have no potential conflicts of interest to disclose.

\section{REFERENCES}

1. European Medicines Agency. Guideline on pharmaceutical development of medicines for paediatric use. EMA/CHMP/QWP/805880/2012 Rev. 2 .

2. World Health Organization. Development of Paediatric Medicines: Points to Consider in Formulation. Geneva, Switzerland: World Health Organization; 2012. WHO Technical Report Series, No. 970, Annex 5.

3. Breitkreutz J, Boos J. Paediatric and geriatric drug delivery. Expert Opin Drug Deliv. 2007;4(1):37-45pmid:17184161

4. Ernest TB, Elder DP, Martini LG, Roberts M, Ford JL. Developing paediatric medicines: identifying the needs and recognizing the challenges. J Pharm Pharmacol. 2007;59(8):1043-1055pmid:17725846

5. European Medicines Agency. Committee for Medicinal products for Human use (CHMP) 2005: Reflection Paper: Formulations of Choice for the Paediatric Population. EMEA/CHMP/PEG/194810/2005

6. Geiling EMK, Cannon PR. Pathological effects of elixir of sulfanilamide poisoning. JAMA. 1938;111(10):919-926

7. Hiller JL, Benda GI, Rahatzad M, et al. Benzyl alcohol toxicity: impact on mortality and intraventricular hemorrhage among very low birth weight infants. Pediatrics. 1986;77(4):500-506

8. Brown WJ, Buist NR, Gipson HT, Huston RK, Kennaway NG. Fatal benzyl alcohol poisoning in a neonatal intensive care unit. Lancet. 1982;1(8283):1250pmid:6123006

9. World Health OrganizationWorld Health Organization. Promoting Safety of Medicines for Children. Geneva, SwitzerlandWorld Health Organization; 2007

10. Nahata MC. Lack of pediatric drug formulations. Pediatrics. 1999;104(3 pt 2, suppl 3):607-609pmid:10469800

11. Ceci A, Felisi M, Baiardi $P$, et al. Medicines for children licensed by the European Medicines Agency (EMEA): the balance after 10 years. Eur J Clin Pharmacol. 2006;62(11):947-952pmid:17021892

12. Shirkey H. Therapeutic orphans. J Pediatr. 1968;72(1):119-120pmid:5634934

13. European Medicines Agency. Report on the Survey of all Paediatric Uses of Medicinal Products in Europe. EMA/794083/2009

14. Bazzano AT, Mangione-Smith R, Schonlau M, Suttorp MJ, Brook RH. Off-label prescribing to children in the United States outpatient setting. Acad Pediatr. 2009;9(2):81-88pmid:19329098

15. Mason J, Pirmohamed M, Nunn TOff-label and unlicensed medicine use and adverse drug reactions in children: a narrative review of the literature. Eur J Clin Pharmacol. 2012;68(1):21-28pmid:21779968

16. Best Pharmaceuticals for Children Act. In: Proceedings of 107th Congress of the United States of America. Washington, DC; January 3, 2002

17. Pediatric Research Equity Act of 2003. In: proceedings of 108th Congress of the United States of America. Washington, DC; January 7, 2003

18. US Food and Drug Administration Amendments Act of 2007. In: Proceedings of 110th Congress of the United States of America. Washington, DC; January 4, 2007

19. The European Parliament and the Council of the European Union. Regulation EC No. 1901/2006 Medicinal Products for Paediatric Use. Official Journal of the European Union L. 378/2. 27.12.2006. Available at: http://ec.europa.eu/health/files/eudralex/vol1/reg_2006_1901/reg_2006_1901_en.pdf. Accessed August 15, 2013

20. World Health Organization. Make medicines child size. Available at: www.who.int/childmedicines/en/. Accessed August 15, 2013

21. BPCA Collaborative Efforts. Inter-agency initiatives. Pediatric formulations platform. Inter-Agency Agreement between the Eunice Kennedy Shriver National Institute of 
Child Health and Human Development (NICHD) and the US Food and Drug Administration (FDA). Available at:

http://bpca.nichd.nih.gov/collaborativeefforts/initiatives/index.cfm. Accessed August 15. 2013

22. European Medicines Agency. Draft 5-year report to the European Commission: general report on the experience acquired as a result of the application of the Paediatric Regulation. July 8, 2012; EMA/428172/2012

23. van Riet-Nales DA, de Jager KE, Schobben AF, Egberts TC, Rademaker CM. The availability and age-appropriateness of medicines authorized for children in The Netherlands. Br J Clin Pharmacol. 2011;72(3):465-473pmid:21477143

24. Balakrishnan K, Grieve J, Tordoff J, Norris P, Reith D. Pediatric licensing status and the availability of suitable formulations for new medical entities approved in the United States between 1998 and 2002. J Clin Pharmacol. 2006;46(9):10381043pmid:16920899

25. Moore P. Children are not small adults. Lancet. 1998;352(9128):630pmid:9746036

26. Kearns GL, Abdel-Rahman SM, Alander SW, Blowey DL, Leeder JS, Kauffman RE. Developmental pharmacology-drug disposition, action, and therapy in infants and children. N Engl J Med. 2003;349(12):1157-1167pmid:13679531

27. Fernandez E, Perez R, Hernandez A, Tejada P, Arteta M, Ramos JT. Factors and mechanisms for pharmacokinetic differences between pediatric population and adults. Pharmaceutics. 2011;3(1):53-72pmid:24310425

28. European Medicines Agency (EMEA) 2000: ICH Topic E 11. Clinical Investigations of Medicinal Products in the Paediatric Population. EMEA/CHMP//CH/2711/99

29. Allegaert K. Neonates need tailored drug formulations. World J Clin Pediatr. 2013;2(1):1-5

30. Noel GJ, Van Den Anker JN, Lombardi D, Ward R. Improving drug formulations for neonates: making a big difference in our smallest patients. J Pediatr. 2012;161(5):947-949pmid:23095694

31. Bartelink IH, Rademaker CM, Schobben AF, van den Anker JN Guidelines on paediatric dosing on the basis of developmental physiology and pharmacokinetic considerations. Clin Pharmacokinet. 2006;45(11):1077-1097pmid:17048973

32. Strolin Benedetti M, Whomsley R, Baltes EL. Differences in absorption, distribution, metabolism and excretion of xenobiotics between the paediatric and adult populations. Expert Opin Drug Metab Toxicol. 2005;1(3):447-471pmid:16863455

33. Strolin Benedetti M, Baltes EL. Drug metabolism and disposition in children. Fundam Clin Pharmacol. 2003;17(3):281-299pmid:12803568

34. Meissner HC, Smith AL The current status of chloramphenicol. Pediatrics. 1979;64(3):348-356pmid:384354

35. Albani M, Wernicke I. Oral phenytoin in infancy: dose requirement, absorption, and elimination. Pediatr Pharmacol (New York). 1983;3(3-4):229-236pmid:6677874

36. Food and Drug Administration. Specific requirements on content and format of labeling for human prescription drugs: revision of "Pediatric Use" subsection in the labeling; final rule. 21 CFR Part 201 (Docket No 92N-0165). Federal Register: December 13, 1994. Available at: http://www.fda.gov/ohrms/dockets/ac/01/briefing/3778b1_Tab6_721CFR\%20Part\%20201.pdf Accessed August 15, 2013

37. Matsui D. Assessing the palatability of medications in children. Paediatr Perinat Drug Ther. 2007;8(2):55-60

38. Cram A, Breitkreutz J, Desset-Brèthes S, Nunn T, Tuleu C, European Paediatric Formulation Initiative (EuPFI). Challenges of developing palatable oral paediatric formulations. Int J Pharm. 2009;365(1-2):1-3pmid:18848611

39. Mennella JA, Beauchamp GK. Optimizing oral medications for children. Clin Ther. 2008;30(11):2120-2132pmid:19108800

40. Davies EH, Tuleu C. Medicines for children: a matter of taste. J Pediatr. 2008;153(5):599-604, e1-e2pmid:18940350

41. Tuleu C, Breitkreutz J. Educational paper: formulation-related issues in pediatric clinical pharmacology. Eur J Pediatr. 2013;172(6):717-720pmid:23111761 
42. Clapham D, Kirsanov D, Legin A, Rudnitskaya A, Saunders K. Assessing taste without using humans: rat brief access aversion model and electronic tongue. Int $\mathrm{J}$ Pharm. 2012;435(2):137-139pmid:22883698

43. Breitkreutz J, Wessel T, Boos J. 13. Dosage forms for oral drug administration. In: Choonara I, Nunn T, Kearns G, eds. Introduction to Paediatric and Perinatal Drug Therapy. Nottingham, UK: Nottingham University Press;2003:189-205

44. Sam T, Ernest TB, Walsh J, Williams JL, European Paediatric Formulation Initiative. (EuPFI). A benefit/risk approach towards selecting appropriate pharmaceutical dosage forms - an application for paediatric dosage form selection. Int J Pharm. 2012;435(2):115-123pmid:22626885

45. Shea KM, American Academy of Pediatrics Committee on Environmental Health. Pediatric exposure and potential toxicity of phthalate plasticizers. Pediatrics. 2003;111(6 pt 1):1467-1474pmid:12777573

46. Haishima Y, Matsuda R, Hayashi Y, Hasegawa C, Yagami T, Tsuchiya T. Risk assessment of di(2-ethylhexyl)phthalate released from PVC blood circuits during hemodialysis and pump-oxygenation therapy. Int J Pharm. 2004;274(1-2):119129pmid:15072788

47. Allegaert $\mathrm{K}$, Anderson BJ, Vrancken $\mathrm{M}$, et al. Impact of a paediatric vial on the magnitude of systematic medication errors in neonates. Paediatr Perinat Drug Ther. 2006;7(2):59-63

48. Mulberg A, Silber S, van den Anker J, eds. Pediatric Drug Development. Concepts and Applications. Hoboken, NJ: J. Wiley \& Sons; 2009

49. UNICEF/WHO. Priority essential medicines for child survival report, Copenhagen, Denmark. Available at: www.who.int/childmedicines/progress/Unicef_prioriry_meds_child_survival.pdf. Accessed August 15, 2013

50. Fabiano V, Mameli C, Zuccotti GV. Paediatric pharmacology: remember the excipients. Pharmacol Res. 2011;63(5):362-365pmid:21241804

51. Nahata MC. Safety of "inert" additives or excipients in paediatric medicines. Arch Dis Child Fetal Neonatal Ed. 2009;94(6):F392-F393pmid:19846397

52. American Academy of Pediatrics Committee on Drugs. "Inactive" ingredients in pharmaceutical products: update (subject review). Pediatrics. 1997;99(2):268278pmid:9024461

53. Hiller JL, Benda GI, Rahatzad M, et al. Benzyl alcohol toxicity: impact on mortality and intraventricular hemorrhage among very low birth weight infants. Pediatrics. 1986;77(4):500-506pmid:3515306

54. Shehab N, Lewis CL, Streetman DD, Donn SM. Exposure to the pharmaceutical excipients benzyl alcohol and propylene glycol among critically ill neonates. Pediatr Crit Care Med. 2009;10(2):256-259pmid:19188870

55. American Academy of Pediatrics. Ethanol in liquid preparations intended for children. Pediatrics. 1984;73(3):405-407pmid:6701068

56. Arulanantham K, Genel MCentral nervous system toxicity associated with ingestion of propylene glycol. J Pediatr. 1978;93(3):515-516pmid:690781

57. Martin G, Finberg L. Propylene glycol: a potentially toxic vehicle in liquid dosage form. J Pediatr. 1970;77(5):877-878pmid:5504082

58. MacDonald MG, Getson PR, Glasgow AM, Miller MK, Boeckx RL, Johnson EL. Propylene glycol: increased incidence of seizures in low birth weight infants. Pediatrics. 1987;79(4):622-625pmid:3822682

59. Glasgow AM, Boeckx RL, Miller MK, MacDonald MG, August GP, Goodman SI. Hyperosmolality in small infants due to propylene glycol. Pediatrics. 1983;72(3):353355pmid: 6889040

60. Balistreri WF, Farrell MK, Bove KE. Lessons from the E-Ferol tragedy. Pediatrics. 1986;78(3):503-506pmid:3748688

61. US Food and Drug Administration. Drug Safety Communication: Serious Health Problems Seen in Premature Babies Given Kaletra (Lopinavir/Ritonavir) Oral Solution. Available at: www.fda.gov/Drugs/DrugSafety/ucm246002.htm. Accessed August 15, 2013 
62. Whittaker A, Currie AE, Turner MA, Field DJ, Mulla H, Pandya HC. Toxic additives in medication for preterm infants. Arch Dis Child Fetal Neonatal Ed. 2009;94(4):F236F240pmid:19158148

63. Lass J, Naelapää K, Shah U, et al. Hospitalised neonates in Estonia commonly receive potentially harmful excipients. BMC Pediatr. 2012;12:136pmid:22931304

64. Salunke S, Giacoia GP, Tuleu C. The STEP (safety and toxicity of excipients for paediatrics) database. Part 1-A need assessment study. Int J Pharm. 2012;435(2):101-111pmid:22583848

65. Salunke S, Brandys B, Giacoia GP, Tuleu C. The STEP (Safety and Toxicity of Excipients for Paediatrics) database: part 2-the pilot version. Int J Pharm. 2013;457(1):310-322pmid:24070789

66. Paediatric Formulation Initiative. STEP database: database of safety and toxicity of excipients for paediatrics. Available at: www.eupfi.org/gpage11.html. Accessed August 15, 2013

67. Turner MA, Storme T. European Study for Neonatal Excipient Exposure (ESNEE). Eur J Hosp Pharm. 2012;19(2):67

68. Schirm E, Tobi H, de Vries TW, Choonara I, De Jong-van den Berg LT. Lack of appropriate formulations of medicines for children in the community. Acta Paediatr. 2003;92(12):1486-1489pmid:14971804

69. Milne CP, Bruss JB. The economics of pediatric formulation development for offpatent drugs. Clin Ther. 2008;30(11):2133-2145pmid:19108801

70. FieldM, BehrmanRInstitute of Medicine (US) Committee on Clinical Research Involving Children. The necessity and challenges of clinical research involving children. In: FieldM, BehrmanR, eds. Ethical Conduct of Clinical Research Involving Children. Washington, DC: National Academies Press; 2004

71. Institute of Medicine (US). Addressing the barriers to pediatric drug development: Workshop summary. Forum on Drug Discovery, Development, and Translation. Washington, DC: The National Academies Press; 2008

72. Balakrishnan K, Tordoff J, Norris P, Reith D. Establishing a baseline for the monitoring of medicines availability for children in the UK: 1998-2002. Br J Clin Pharmacol. 2007;63(1):85-91pmid:16869822

73. Chui J, Tordoff J, Kennedy J, Reith D. Trends in accessibility to medicines for children in New Zealand: 1998-2002. Br J Clin Pharmacol. 2004;57(3):322327pmid:14998428

74. Chui J, Tordoff J, Reith D. Changes in availability of paediatric medicines in Australia between 1998 and 2002. Br J Clin Pharmacol. 2005;59(6):736-742pmid:15948941

75. Osterberg RE. 4. FDA Approach to Pediatric Testing. In: Hoberman AM, Lewis EM, eds. Pediatric Nonclinical Drug Testing: Principles, Requirements, and Practices. Hoboken, NJ: John Wiley \& Sons, Inc; 2012:59-78pmid:15948941

76. European Medicines Agency. Report on the survey of all paediatric uses of medicinal products in Europe. December 10, 2010, EMA/794083/2009

77. Tobias LD, Harkness J. IAPO Briefing Paper on Paediatric Medicines and Clinical Research (November 2006). International Alliance of Patients' Organizations (IAPO) Available at: www.patientsorganizations.org/paediatrics. Accessed May 23, 2014

78. Nahata MC, Allen LV Jr. Extemporaneous drug formulations. Clin Ther. 2008;30(11):2112-2119pmid:19108799

79. Choonara I, Conroy S. Unlicensed and off-label drug use in children: implications for safety. Drug Saf. 2002;25(1):1-5pmid:11820908

80. European Medicines Agency. Evidence of Harm From Off-Label or Unlicensed Medicines in Children. EMEA/126327. EMEA; 2004

81. Shah SS, Hall M, Goodman DM, et al. Off-label drug use in hospitalized children. Arch Pediatr Adolesc Med. 2007;161(3):282-290pmid:17339510

82. Cuzzolin L, Atzei A, Fanos V. Off-label and unlicensed prescribing for newborns and children in different settings: a review of the literature and a consideration about drug safety. Expert Opin Drug Saf. 2006;5(5):703-718pmid:16907660

83. Pandolfini $C$, Bonati M. A literature review on off-label drug use in children. Eur J Pediatr. 2005;164(9):552-558pmid:15912383 
84. Lowey A, Jackson M. Handbook of Extemporaneous Formulation—A Guide to Pharmaceutical Compounding. London, UK: Pharmaceutical Press; 2010

85. Best BM, Capparelli EV, Diep H, et al. Pharmacokinetics of lopinavir/ritonavir crushed versus whole tablets in children. J Acquir Immune Defic Syndr. 2011;58(4):385-391pmid:21876444

86. Kairuz TE, Gargiulo D, Bunt C, Garg S. Quality, safety and efficacy in the 'off-label' use of medicines. Curr Drug Saf. 2007;2(1):89-95pmid:18690954

87. PharmInfoTech. eMixt database: database of oral liquid formulations. Available at: www.pharminfotech.co.nz/manual/Formulation/mixtures/. Accessed August 15, 2013

88. Boots I, Sukhai RN, Klein RH, et al. Stimulation programs for pediatric drug research—do children really benefit? Eur J Pediatr. 2007;166(8):849855pmid:17225950

89. European Medicines Agency. General report on the experience acquired as a result of the application of the Paediatric Regulation. Summary of the replies to the public consultation. SANCO/D5/FS/ci D(2013) 27105 Available at: http://ec.europa.eu/health/files/paediatrics/2013_pc_paediatrics/2013_paediatric_rep ort_summary.pdf. Accessed August 15, 2013

90. Best Pharmaceuticals for Children Act (BPCA). Priority List of Needs in Pediatric Therapeutics, 2012. Eunice Kennedy Shriver National Institute of Child Health and Human Development (NICHD). Best Pharmaceuticals for Children Act. Available at: http://bpca.nichd.nih.gov/prioritization/upload/2012_Priority_List_FINAL.pdf. Accessed August 15, 2013

91. European Medicines Agency. Revised priority list for studies into off-patent paediatric medicinal products. EMA/98717/2012, August 2013. Available at: www.ema.europa.eu/docs/en_GB/document_library/Other/2009/10/WC500004017.p df. Accessed August 15, 2013

92. World Health Organization. Report of the informal expert meeting on dosage forms of medicines for children. WHO Headquarters, Geneva, Switzerland, 2008. Available at: www.who.int/selection_medicines/committees/expert/17/application/paediatric/Dosa ge form_reportDEC2008.pdf. Accessed August 15, 2013

93. World Health Organization. WHO model list of essential medicines for children, 4th list. WHO, Geneva, April 2013.

www.who.int/medicines/publications/essentialmedicines/4th_EMLC_FINAL_web_8Ju I13.pdf. Accessed August 15, 2013

94. World Health Organization. Priority life-saving medicines for women and children 2012 Geneva, WHO/EMP/MAR/2012. Available at: http://apps.who.int/iris/bitstream/10665/75154/1/WHO_EMP_MAR_2012.1_eng.pdf. Accessed August 15, 2013

95. World Health Organization. WHO Model Formulary for Children. WHO, Geneva, Available at: www.who.int/selection_medicines/list/WMFc_2010.pdf. Accessed August 15, 2013

96. World Health Organization. Maternal, newborn, child and adolescent health. Documents on child health. Available at: www.who.int/maternal_child_adolescent/documents/child/en/. Accessed August 15, 2013

97. World Health Organization. WHO List of Prequalified Medicinal Products. Available at: http://apps.who.int/prequal/97. Accessed August 15, 2013

98. National Institutes of Health (NICHD) Funding Opportunities. Development of appropriate pediatric formulations and pediatric drug delivery systems (R01, R03, R21, R41/R43). Available at: http://grants.nih.gov/grants/guide. Accessed August 15, 2013

99. Zajicek AThe National Institutes of Health and the Best Pharmaceuticals for Children Act. Paediatr Drugs. 2009;11(1):45-47pmid:19127953

100. European Commission. EU Research Projects FP7 Health. CORDIS (Community Research and Development Information Centre). Available at: http://cordis.europa.eu/projects/home_en.html. Accessed August 15, 2013 
101. Pediatric Formulations Platform. BPCA, National Institutes of Health. Interagency agreement between the Eunice Kennedy Shriver National Institute of Child Health and Human Development (NICHD) and the US Food and Drug Administration (FDA). Oral formulations platform-report

102. Nunn $\mathrm{T}$, Williams JFormulation of medicines for children. $\mathrm{Br} \mathrm{J}$ Clin Pharmacol. 2005;59(6):674-676pmid:15948931

103. Stoltenberg I, Winzerburg G, Breitkreutz J Solid oral forms for childrenformulations, excipients and acceptance issues. J App Ther Res. 2010;7(4):141-146

104. Abdulla S, Sagara I, Borrmann S, et al Efficacy and safety of artemetherlumefantrine dispersible tablets compared with crushed commercial tablets in African infants and children with uncomplicated malaria: a randomised, single-blind, multicentre trial. Lancet. 2008;372(9652):1819-1827

105. Kayitare E, Vervaet C, Ntawukulilyayo JD, Seminega B, Bortel V, Remon JP. Development of fixed dose combination tablets containing zidovudine and lamivudine for paediatric applications. Int J Pharm. 2009;370(1-2):4146pmid:19059324

106. Vanprapar N, Cressey TR, Chokephaibulkit K, et al. IMPAACT P1056 Team. A chewable pediatric fixed-dose combination tablet of stavudine, lamivudine, and nevirapine: pharmacokinetics and safety compared with the individual liquid formulations in human immunodeficiency virus-infected children in Thailand. Pediatr Infect Dis J. 2010;29(10):940-944pmid:20453709

107. Chokephaibulkit K, Cressey TR, Capparelli E, et al., IMPAACT P1069 Team. Pharmacokinetics and safety of a new paediatric fixed-dose combination of zidovudine/lamivudine/nevirapine in HIV-infected children. Antivir Ther. 2011;16(8):1287-1295pmid:22155910

108. Larka. Press release. Aptalis announces European Commission approval for new formulation of Viread. Available at: www.pharmaceuticaltechnology.com/contractors/drug_delivery/eurand/pressaptalis-ec-approval-newformulation-of-viread.html. Accessed August 15, 2013

109. Eisai Inc. Press release. FDA approves ACIPHEX Sprinkle (Rabeprazole Sodium) for use in children ages 1 to 11 . Available at: http://us.eisai.com/wps/wcm/connect/Eisai/Home/Press+Room/Press+Releases/201 3/FDAapprovesaciphexsprinkle.html. Accessed August 15, 2013

110. World Health Organization. Benznidazole: child-adapted dosage form approved. WHO Drug Information. 2012;26(1):21-22

111. Food and Drug Administration. Lamictal medication guide. Available at: www.fda.gov/downloads/Drugs/DrugSafety/UCM152835.pdf. Accessed August 15, 2013

112. Drug Information online. Press release 2012: FDA approves Zuplenz. Available at: www.drugs.com/newdrugs/fda-approves-strativa-pharmaceuticalszuplenz-ondansetron-oral-soluble-film-2208.html. Accessed August 15, 2013

113. Stoltenberg I, Breitkreutz J. Orally disintegrating mini-tablets (ODMTs)—a novel solid oral dosage form for paediatric use. Eur J Pharm Biopharm. 2011;78(3):462-469pmid:21324357

114. Pfizer Medic and News 2009. Pfizer announces European Union approval of a new form of Lipitor (atorvastatin) for use in children. Available at: http://press.pfizer.com/press-release/pfizer-announces-european-union-approvalnew-form-lipitor-atorvastatin-use-children. Accessed August 15, 2013

115. Merck News Room. FDA approves Merck's ISENTRESS (raltegravir) for use in children ages two years and older as part of HIV-1 combination therapy. Available at: www.mercknewsroom.com/press-release/prescription-medicine-news/fdaapproves-mercks-isentress-raltegravir-use-children-ages. Accessed August 15, 2013

116. Breitkreutz J. Arzneiformen für Kinder. Nach der EU-Reform. Pharmazie in unserer Zeit 2009;38(1):30-37.pmid:19132675

117. Yeung VW, Wong IC. When do children convert from liquid antiretroviral to solid formulations? Pharm World Sci. 2005;27(5):399-402pmid:16341747 
118. Garvie PA, Lensing S, Rai SN. Efficacy of a pill-swallowing training intervention to improve antiretroviral medication adherence in pediatric patients with HIVIAIDS. Pediatrics. 2007;119(4). Available at: www.pediatrics.org/cgi/content/full/119/4/e893pmid:17353298

119. Thomson SA, Tuleu C, Wong IC, Keady S, Pitt KG, Sutcliffe AG. Minitablets: new modality to deliver medicines to preschool-aged children. Pediatrics. 2009;123(2): Available at www.pediatrics.org/cgi/content/full/123/2/e235pmid:19171575

120. Spomer N, Klingmann V, Stoltenberg I, et al. Acceptance of uncoated minitablets in young children: results from a prospective exploratory cross-over study. Arch Dis Child. 2012;97(3):283-286pmid:22253279

121. Klingmann V, Spomer N, Lerch C, et al. Favorable acceptance of minitablets compared with syrup: a randomized controlled trial in infants and preschool children. J Pediatr. 2013;163(6):1728-1732.e1

122. Walsh J, Bickmann D, Breitkreutz J, Chariot-Goulet M, European Paediatric Formulation Initiative (EuPFI). Delivery devices for the administration of paediatric formulations: overview of current practice, challenges and recent developments. Int J Pharm. 2011;415(1-2):221-231pmid:21640807

123. World Health Organization. Priority medicines for Europe and the World Update Report. WHO Geneva, 2013. Available at:

www.who.int/medicines/areas/priority_medicines/en/. Accessed August 15, 2013

124. Ricci BM. Bridging studies in support of oral pediatric formulation development. Int J Pharm. 2013;457(1):323-326pmid:23942015

125. Havenaar R, Anneveld B, Hanff LM, et al. In vitro gastrointestinal model (TIM) with predictive power, even for infants and children? Int J Pharm. 2013;457(1):327-332pmid:23906665

126. Dunne J, Rodriguez WJ, Murphy MD, et al. Extrapolation of adult data and other data in pediatric drug-development programs. Pediatrics. 2011;128(5).

Available at: www.pediatrics.org/cgi/content/full/128/5/e1242pmid:22025597

127. Giacoia GP, Taylor-Zapata P, Zajicek A Eunice Kennedy Shriver National Institute of Child Health and Human Development Pediatrics Formulation Initiative: proceedings from the Second Workshop on Pediatric Formulations. Clin Ther. 2012;34(11):S1-S10pmid:23149008

128. Menjoge AR, Kannan RM, Tomalia DA. Dendrimer-based drug and imaging conjugates: design considerations for nanomedical applications. Drug Discov Today. 2010;15(5-6):171-185pmid:20116448

129. Timko BP, Kohane DS. Materials to clinical devices: technologies for remotely triggered drug delivery. Clin Ther. 2012;34(11):S25-S35pmid:23149010

130. Krishnan V, Xu X, Barwe SP, et al. Dexamethasone-loaded block copolymer nanoparticles induce leukemia cell death and enhance therapeutic efficacy: a novel application in pediatric nanomedicine. Mol Pharm. 2013;10(6):21992210pmid:23194373

131. van Riet-Nales DA, Schobben AF, Egberts TC, Rademaker CM. Effects of the pharmaceutical technologic aspects of oral pediatric drugs on patient-related outcomes: a systematic literature review. Clin Ther. 2010;32(5):924938pmid:20685501

132. United States Government Accountability Office. Pediatric medical devices. Provisions support development, but better data needed for required reporting. Report to Congressional Committees. Available at: www.gao.gov/assets/590/587164.pdf. Accessed August 15, 2013 
Ivanovska, V., Rademaker, C.M.A., Dijk, L. van, Mantel-Teeuwisse, A.K. Pediatric drug formulations: a review of challenges and progress. Pediatrics: 2014, 134(2), 361-372

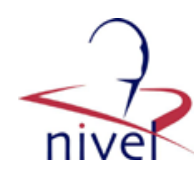

TABLES

TABLE 1 Potential Clinical Advantages and Disadvantages of Different Formulations and Routes of Administration in Children 1,25,43-47

\begin{tabular}{|c|c|c|}
\hline Administration and Dosage Forms & Potential Advantages & Potential Disadvantages \\
\hline \multirow{3}{*}{$\begin{array}{l}\text { Oral } \\
\text { Liquid preparations } \\
\bullet \text { Suspensions }\end{array}$} & Main route for (long-term) treatments in children & First-pass effect \\
\hline & Acceptability from term birth & Instability of multidose preparations \\
\hline & Maximum dose flexibility & $\begin{array}{l}\text { Age-appropriate dosing volume for full-dose ingestion } \\
\qquad(<5 \mathrm{~mL} \text { in younger and }<10 \mathrm{~mL} \text { in older age groups })\end{array}$ \\
\hline - Solutions, syrup, drops & Stability, portability, good dosage uniformity & \\
\hline $\begin{array}{l}\text { - Powders and granules } \\
\text { for reconstitution }\end{array}$ & Options for different doses and modified release & Dose-measuring device critical \\
\hline Solid dosage forms & Better acceptability (with liquid/semi-solid food) & Shaking for dose accuracy (suspensions) \\
\hline • Tablets & Dose flexibility & Incorrect dosing for oral drops (criticality of dose) \\
\hline 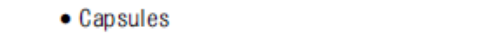 & Ease of administration & Risks of administration without prior dispersion/dissolution \\
\hline $\begin{array}{l}\text { - Powders, granules, sprinkles, } \\
\text { multiparticulates, mini-tablets }\end{array}$ & Can be used in neonates and seriously ill infants & Ability to swallow intact dosage forms \\
\hline - Orodispersible/chewable preparations & & Risks of choking and chewing \\
\hline \multirow[t]{12}{*}{ Administration through nasogastric tubes } & & Limited dose flexibility \\
\hline & & Dose-measuring device needed \\
\hline & & Compatibility with food/drinks \\
\hline & & Limited control over dose intake \\
\hline & & Taste-masking requirements \\
\hline & & Less stable than standard tablets \\
\hline & & Risk of direct swallowing \\
\hline & & Intellectual properties costs \\
\hline & & $\begin{array}{l}\text { Ease of administration and dosing accuracy } \\
\text { (volume, density, viscosity, particle size) }\end{array}$ \\
\hline & & Potential compatibility with feeding tube material \\
\hline & & Doses and rinse volume relevant to target age group \\
\hline & & Relevant size of feeding tubes \\
\hline Parenteral ${ }^{1,2,5,43-47}$ & Main route for neonates and emergency cases & Infections, phlebitis, embolism \\
\hline - Intravenous injections & $\begin{array}{l}\text { Quick/high/constant blood and } \\
\text { tissue drug concentration }\end{array}$ & Fluid overload, electrolyte imbalance \\
\hline - Subcutaneous injections & Sustained-release preparations & Inappropriate diluents \\
\hline - Intramuscular injections & & Measurement of dose volumes \\
\hline \multirow[t]{4}{*}{ - Pump systems } & & Lag-volume effects in intravenous line \\
\hline & & Small veins, punctuation pain, needle phobia \\
\hline & & Incompatibilities with coadministered intravenous medicines \\
\hline & & $\begin{array}{l}\text { Drug migration into plastic tubes (plasticizer desorption of } \\
\text { phthalates from circuits) }\end{array}$ \\
\hline $\operatorname{Rectal}^{1,2,5,43}$ & $\begin{array}{l}\text { Can be used in severely ill children } \\
\text { or those unable to swallow }\end{array}$ & Size considerations \\
\hline - Suppositories & & $\begin{array}{l}\text { Limited bioavailability (minor absorption area, } \\
\text { lack of active drug transporters, small fluid volume for } \\
\text { dissolution) }\end{array}$ \\
\hline \multicolumn{3}{|l|}{ - Rectal liquids } \\
\hline & & $\begin{array}{l}\text { Frequent stooling in breast-fed infants, uncontrolled } \\
\text { defecation in infants }\end{array}$ \\
\hline & & Lower compliance and concordance \\
\hline & & Cultural and regional acceptance barriers \\
\hline Topical, transdermal ${ }^{1,2,5}$ & Provision of constant blood levels & $\begin{array}{l}\text { Unintended systemic absorption/toxicity risk in neonates } \\
\text { (large skin surface area, thickness, hydration, perfusion) }\end{array}$ \\
\hline - Transdermal patches & Painless and easy administration of bolus & \\
\hline - Medicated plasters & Sustained drug delivery & Natural barrier for penetration of many drugs \\
\hline \multirow[t]{3}{*}{ - 0 intments/creams/gels/liquids } & & Safety of excipients \\
\hline & & Local skin irritation \\
\hline & & Deliberate removal of patches/plasters \\
\hline \multirow{3}{*}{$\begin{array}{l}\text { Nasal }{ }^{1,2,5} \\
\text { - Solutions, drops } \\
\text { - Semisolid dosage forms }\end{array}$} & Good nasal transmucosal bioavailability & Unwanted systemic effect \\
\hline & Needle-free access to systemic circulation & Irritation of the mucosa \\
\hline & & Ineffective in abundant secretion \\
\hline Pulmonary ${ }^{1,25}$ & Avoidance of hepatic first-pass metabolism & $\begin{array}{l}\text { Increased deposition in upper/central airways } \\
\text { (small airway diameter) }\end{array}$ \\
\hline $\begin{array}{l}\text { - Metered dose inhaler with } \\
\text { spacer/facemask }\end{array}$ & Painless application & $\begin{array}{l}\text { Decreased total lung deposition (reduced motor } \\
\text { abilities/low inspiration volume) }\end{array}$ \\
\hline - Nebulizers (older children) & & Device use critical to improve inhaled doses \\
\hline - Dry powder inhalers (older children) & & \\
\hline
\end{tabular}


Ivanovska, V., Rademaker, C.M.A., Dijk, L. van, Mantel-Teeuwisse, A.K. Pediatric drug formulations: a review of challenges and progress. Pediatrics: 2014, 134(2), 361-372

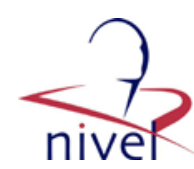

TABLE 2 Examples of Excipients With
Elevated Toxicity and Safety Risks
for (Preterm and Term) Newborns
and Infants $<6$ Months of Age

TABLE 3 Examples of Recently Marketed/Prequalified Novel Oral Drug Formulations for Children $97,104,108-116$

\begin{tabular}{|c|c|c|}
\hline Dosage Form & International Nonproprietary Name & Regulatory Agency Authorization/WHO PQ Year \\
\hline \multicolumn{3}{|l|}{ Multi-particulates ${ }^{97,108-110}$} \\
\hline \multirow[t]{3}{*}{ Sprinkles, granules and pellets } & Para-aminosalicylate granules & WH0 PQ 2009 \\
\hline & TFV granules & FDA 2012, EMA 2012 \\
\hline & Rabeprazole sprinkles & FDA 2013 \\
\hline \multicolumn{3}{|l|}{ Flexible dispersible formulations ${ }^{97,104,111-114}$} \\
\hline \multirow[t]{16}{*}{ Dispersible and orodispersible tablets } & Artemether/lumefantrine dispersible tablets & $\begin{array}{l}\text { Swissmedic } 2008 \text { / } \\
\text { WH0 PQ } 2009\end{array}$ \\
\hline & 3TC/NVP/d4T & WHO PQ 2008 \\
\hline & Isoniazid/pyrazinamide/rifampicin & WH0 PQ 2009 \\
\hline & Isoniazid/rifampicin & WHO PQ 2009 \\
\hline & 3TC/NVP/AZT (Mylan Laboratories) & WHO PQ 2009 \\
\hline & $\mathrm{ABC}$ & WHO PQ 2010 \\
\hline & $3 \mathrm{TC} / \mathrm{d} 4 \mathrm{~T}$ & WH0 PQ 2011 \\
\hline & 3TC/AZT & WH0 PQ 2011 \\
\hline & EFV & WHO PQ 2012 \\
\hline & 3TC & WH0 PQ 2012 \\
\hline & Artemether/lumefantrine & WHO PQ 2012 \\
\hline & Isoniazid/pyrazinamide/rifampicin & WH0 PQ 2012 \\
\hline & Isoniazid/rifampicin & WH0 PQ 2012 \\
\hline & Benznidazole & WH0 PQ 2012 \\
\hline & Lamotrigine orodispersible tablets & FDA 2012 \\
\hline & AZT & WH0 PQ 2013 \\
\hline Orodispersible films (wafer) & Ondasetron & FDA 2010 \\
\hline Chewable dispersible tablets & Lamotrigine & FDA 2012 \\
\hline Orally disintegrating mini-tablets & Hydrochlorothiazide & Model drug under investigation \\
\hline \multicolumn{3}{|l|}{ Other novel oral formulations $\mathrm{s}^{15,116}$} \\
\hline \multirow{2}{*}{ Chewable tablets } & Atorvastatin & EMA 2011 \\
\hline & Raltegravir & FDA 2012 \\
\hline
\end{tabular}

3TC, lamivudine; ABC, abacavir; AZT, zidovudine; d4T, stavudine; EFV, efavirenz; FDA, US Food and Drug Administration; ODT, orodispersible tablet; PQ, prequalification; NVP, nevirapine; TFV, tenofovir. 
Ivanovska, V., Rademaker, C.M.A., Dijk, L. van, Mantel-Teeuwisse, A.K. Pediatric drug formulations: a review of challenges and progress. Pediatrics: 2014, 134(2), 361-372

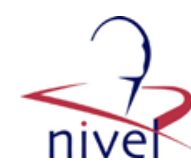

TABLE 4 Examples of Novel Drug Devices That Facilitate Oral Administration of Medicines in Children ${ }^{3,116,122}$

\begin{tabular}{|c|c|c|}
\hline Novel Drug Devices & $\begin{array}{l}\text { Examples of Medicines Administered With Drug } \\
\text { Devices (Brand Name, Manufacturer) }\end{array}$ & Purpose of Use \\
\hline Modified teat/pacifier with drug-loaded reservoir & Nystatin (Mykundex, Bioglan Giessen, Germany) & $\begin{array}{l}\text { Constant delivery of medicine (in oral cavity) in } \\
\text { neonates/infants }\end{array}$ \\
\hline Dosing spoon filled with liquid medicine & $\begin{array}{l}\text { Diphenhydramine (Benadryl, Pfizer Consumer } \\
\text { Healthcare, Madison, New Jersey) }\end{array}$ & Exact measurement of single doses, low risk of spillage \\
\hline Coated particles on dosage spoon (pulp-spoon) & $\begin{array}{l}\text { Azythromycin powder for oral pulp (predosed } \\
\text { azithromycin spoon; Sandoz Kundl, Austria) }\end{array}$ & $\begin{array}{l}\text { Exact measurement of single doses, low risk of spillage } \\
\text { improves stability of medicines }\end{array}$ \\
\hline Dropper tube & $\begin{array}{l}\text { Codeine drops (Paracodin, Abbott Laboratories, } \\
\text { Abbott Park, IL) }\end{array}$ & Ensures dose uniformity \\
\hline $\begin{array}{l}\text { Dose-sipping technology (straw with } \\
\text { medicine and beverage) }\end{array}$ & $\begin{array}{l}\text { Clarithromycin micropellets (Clarosip, Grünenthal } \\
\text { GmbH, Aachen, Germany) }\end{array}$ & Improves palatability and adherence \\
\hline Solid dosing pen & Carvedilol/metoprolol tartrate (model drugs) & Exact measurement of doses \\
\hline
\end{tabular}

